
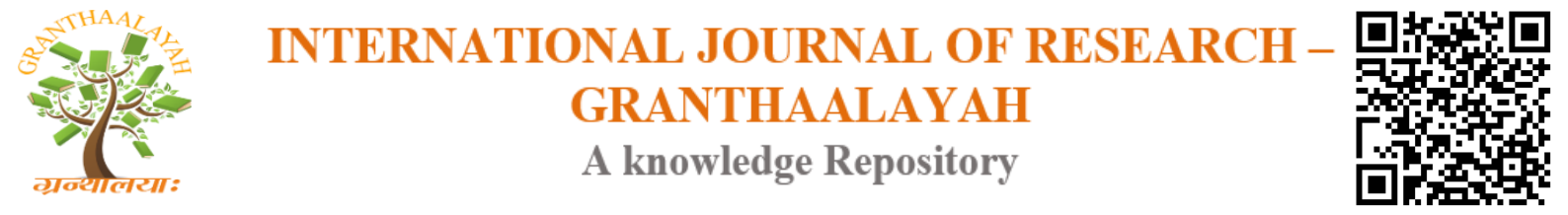

Science

\title{
REAL POWER LOSS REDUCTION BY ENRICHED GENETIC ALGORITHM
}

\author{
Dr.K.Lenin ${ }^{* 1}$ \\ ${ }^{* 1}$ Professor, Department of EEE, Prasad V.Potluri Siddhartha Institute of Technology, Kanuru, \\ Vijayawada, Andhra Pradesh -520007, India
}

\begin{abstract}
In this paper, Enriched Genetic Algorithm (EGA) utilized to solve reactive power optimization problem. In the proposed algorithm Stochastic Universal Selection (SS) is utilized to improve the selection procedure. The selection method in Genetic algorithm (GA) plays a significant role in the runtime to get the optimized solution as well as in the superiority of the solution. In this work, an enriched selection technique is presented which uphold both fast runtime and elevated quality solution. Proposed EGA algorithm has been tested in standard IEEE 118 \& practical 191 bus test systems and simulation results show clearly the advanced performance of the proposed algorithm in reducing the real power loss.
\end{abstract}

Keywords: Optimal Reactive Power; Transmission Loss; Enriched Genetic Algorithm.

Cite This Article: Dr.K.Lenin. (2017). "REAL POWER LOSS REDUCTION BY ENRICHED GENETIC ALGORITHM." International Journal of Research - Granthaalayah, 5(8), 18-25. https://doi.org/10.29121/granthaalayah.v5.i8.2017.2178.

\section{Introduction}

Optimal reactive power problem is to minimize the real power loss and bus voltage deviation. Various numerical methods like the gradient method [1-2], Newton method [3] and linear programming [4-7] have been adopted to solve the optimal reactive power dispatch problem. Both the gradient and Newton methods have the complexity in managing inequality constraints. If linear programming is applied then the input- output function has to be uttered as a set of linear functions which mostly lead to loss of accuracy. The problem of voltage stability and collapse play a major role in power system planning and operation [8]. Evolutionary algorithms such as genetic algorithm have been already proposed to solve the reactive power flow problem [9-11]. Evolutionary algorithm is a heuristic approach used for minimization problems by utilizing nonlinear and non-differentiable continuous space functions. In [12], Hybrid differential evolution algorithm is proposed to improve the voltage stability index. In [13] Biogeography Based algorithm is projected to solve the reactive power dispatch problem. In [14], a fuzzy based method is used to solve the optimal reactive power scheduling method. In [15], an improved evolutionary programming is used to solve the optimal reactive power dispatch problem. In [16], 
the optimal reactive power flow problem is solved by integrating a genetic algorithm with a nonlinear interior point method. In [17], a pattern algorithm is used to solve ac-dc optimal reactive power flow model with the generator capability limits. In [18], F. Capitanescu proposes a two-step approach to evaluate Reactive power reserves with respect to operating constraints and voltage stability. In [19], a programming based approach is used to solve the optimal reactive power dispatch problem. In [20], A. Kargarian et al present a probabilistic algorithm for optimal reactive power provision in hybrid electricity markets with uncertain loads. This paper proposes Enriched Genetic Algorithm (EGA) is proposed to solve the reactive power problem. In the proposed algorithm Stochastic Universal Selection (SS) is utilized to improve the selection [21] procedure. The selection method in Genetic algorithm (GA) plays a significant role in the runtime to get the optimized solution as well as in the superiority of the solution. In this work, an enriched selection technique is presented which uphold both fast runtime and elevated quality solution. Proposed EGA has been evaluated in standard IEEE 118 \& practical 191 bus test systems. Simulation results show that our projected approach outperforms all the entitled reported algorithms in minimization of real power loss.

\section{Problem Formulation}

The optimal power flow problem is treated as a general minimization problem with constraints, and can be mathematically written in the following form:

Minimize $\mathrm{f}(\mathrm{x}, \mathrm{u})$

subject to $\mathrm{g}(\mathrm{x}, \mathrm{u})=0$

and

$\mathrm{h}(\mathrm{x}, \mathrm{u}) \leq 0$

where $f(x, u)$ is the objective function. $g(x . u)$ and $h(x, u)$ are respectively the set of equality and inequality constraints. $\mathrm{x}$ is the vector of state variables, and $\mathrm{u}$ is the vector of control variables. The state variables are the load buses (PQ buses) voltages, angles, the generator reactive powers and the slack active generator power:

$\mathrm{x}=\left(\mathrm{P}_{\mathrm{g} 1}, \theta_{2}, \ldots, \theta_{\mathrm{N}}, \mathrm{V}_{\mathrm{L} 1}, ., \mathrm{V}_{\mathrm{LNL}}, \mathrm{Q}_{\mathrm{g} 1}, \ldots, \mathrm{Q}_{\mathrm{gng}}\right)^{\mathrm{T}}$

The control variables are the generator bus voltages, the shunt capacitors/reactors and the transformers tap-settings:

$\mathrm{u}=\left(\mathrm{V}_{\mathrm{g}}, \mathrm{T}, \mathrm{Q}_{\mathrm{c}}\right)^{\mathrm{T}}$

or

$\mathrm{u}=\left(\mathrm{V}_{\mathrm{g} 1}, \ldots, \mathrm{V}_{\mathrm{gng}}, \mathrm{T}_{1}, \ldots, \mathrm{T}_{\mathrm{Nt}}, \mathrm{Q}_{\mathrm{c} 1}, \ldots, \mathrm{Q}_{\mathrm{cNc}}\right)^{\mathrm{T}}$

Where ng, nt and nc are the number of generators, number of tap transformers and the number of shunt compensators respectively.

\section{Objective Function}

\subsection{Active Power Loss}

The objective of the reactive power dispatch is to minimize the active power loss in the transmission network, which can be described as follows: 
$F=P L=\sum_{k \in N b r} g_{k}\left(V_{i}^{2}+V_{j}^{2}-2 V_{i} V_{j} \cos \theta_{i j}\right)$

or

$F=P L=\sum_{i \in N g} P_{g i}-P_{d}=P_{g s l a c k}+\sum_{i \neq s l a c k}^{N g} P_{g i}-P_{d}$

where $g_{k}$ : is the conductance of branch between nodes $\mathrm{i}$ and $\mathrm{j}$, Nbr: is the total number of transmission lines in power systems. $\mathrm{P}_{\mathrm{d}}$ : is the total active power demand, $\mathrm{P}_{\mathrm{gi}}$ : is the generator active power of unit $\mathrm{i}$, and $\mathrm{P}_{\text {gsalck: }}$ : is the generator active power of slack bus.

\section{Voltage Profile Improvement}

For minimizing the voltage deviation in PQ buses, the objective function becomes:

$F=P L+\omega_{v} \times V D$

where $\omega_{\mathrm{v}}$ : is a weighting factor of voltage deviation.

$\mathrm{VD}$ is the voltage deviation given by:

$V D=\sum_{i=1}^{N p q}\left|V_{i}-1\right|$

\section{Equality Constraint}

The equality constraint $\mathrm{g}(\mathrm{x}, \mathrm{u})$ of the ORPD problem is represented by the power balance equation, where the total power generation must cover the total power demand and the power losses:

$P_{G}=P_{D}+P_{L}$

This equation is solved by running Newton Raphson load flow method, by calculating the active power of slack bus to determine active power loss.

\section{Inequality Constraints}

The inequality constraints $\mathrm{h}(\mathrm{x}, \mathrm{u})$ reflect the limits on components in the power system as well as the limits created to ensure system security. Upper and lower bounds on the active power of slack bus, and reactive power of generators:

$P_{\text {gslack }}^{\min } \leq P_{\text {gslack }} \leq P_{\text {gslack }}^{\max }$

$Q_{g i}^{\min } \leq Q_{g i} \leq Q_{g i}^{\max }, i \in N_{g}$

Upper and lower bounds on the bus voltage magnitudes:

$V_{i}^{\min } \leq V_{i} \leq V_{i}^{\max }, i \in N$

Upper and lower bounds on the transformers tap ratios:

$T_{i}^{\text {min }} \leq T_{i} \leq T_{i}^{\max }, i \in N_{T}$

Upper and lower bounds on the compensators reactive powers: 
$Q_{c}^{\min } \leq Q_{c} \leq Q_{C}^{\max }, i \in N_{C}$

Where $\mathrm{N}$ is the total number of buses, $\mathrm{N}_{\mathrm{T}}$ is the total number of Transformers; $\mathrm{N}_{\mathrm{c}}$ is the total number of shunt reactive compensators.

\section{Simple Genetic Algorithm}

Genetic algorithm (GA) is search algorithms based on the mechanics of natural genetics and natural selection. The GA is a population search method. A population of strings is kept in each Generation. The simulation of the natural processes of reproduction, gene crossover and mutation produces the next generation.

\section{Reproduction}

Reproduction is simply an operation whereby an old chromosome is copied into a "mating pool" according to its fitness value. More highly fitted chromosomes receive a greater number of copies in the next generation. Copying chromosomes according to their fitness values means that chromosomes with a higher value have a higher probability of contributing one or more offspring in the next generation.

\section{Crossover}

Crossover is the primary genetic operator, which promotes the exploration of new regions in the search space. It is a structured, yet randomized mechanism of exchanging informing between strings. This operation is similar to that of two scientists exchanging information. Crossover begins by selecting at random two members previously placed in the mating pool during reproduction. A crossover point is then selected at random and information from one parent, up to the crossover point is exchanged with the other member, thus creating two new members for the next generation.

\section{Mutation}

Although reproduction and crossover effectively search and recombine existing chromosomes, they do not create any new genetic material in the population. Mutation is capable of overcoming this shortcoming. It is an occasional (with small probability) random alternation of a chromosome position.

\section{Fitness Function}

The fitness function is the one which gives a raw measure of among the fitness to each possible candidate solution in the problem space.

For a minimization function, the fitness function is taken as

$$
\mathrm{FIT}=1 / 1+\phi
$$

\section{Selection Method}

Here, Roulette wheel selection method is followed. This is fitness proportional selection mechanism. The better fit strings get selected often to pass on their information to their off springs. 


\section{Enriched Selection Method for GA}

Stochastic Universal Selection (SS) is utilized to improve the selection procedure. In the SS, the sum $(\mathrm{T})$ of the chosen winner is computed and modernized during the procedure. For a fresh individual to be elected to the group, the value of the fresh member should be less than $\mathrm{T}$.

The probability is computed by,

$P S(i)=\frac{f_{i}}{f_{\text {maximum }}}$

Where $f_{i}$ is the fitness value of an individual $i$ which is chosen and $f_{\max }$ is the maximum fitness in the population.

In this paper, the way of selection of an individual improved for the next generation. And it described as follows,

a. Select any individual from the population arbitrarily.

b. Sorting out the fitness value of the preferred individual by the entire number of population to discover the preliminary point, as shown below,

preliminary point $=\frac{f_{\text {random }}}{\text { population size }}$

To discover out the probability of chosen individual the following steps are utilized:

c. Discover the lowest fitness value in the population which has the smallest distance over the cities, where the time complication is equal to $\mathrm{O}(\mathrm{n})$.

d. Choose individuals whose fitness values are less than the smallest fitness value plus a proportion $P$ which is situated between $\mathbf{0}<\boldsymbol{P}<\mathbf{1}$, as shown below:

$P S(i)=\frac{f_{i}}{f_{\text {best }}+P}$

Where $(i)$ is the fitness which is selected, $f_{\text {best }}$ is the most excellent fitness (lowest fitness value) in the existing population, and $\mathrm{P}$ is percentage that is added to the most excellent fitness.

\section{Enriched Selection Procedure}

Input: Fitness $f$ is the most excellent fitness of the existing generation, and $O s$ size or number of population.

Output: population $O$ such that fitness $(O)<f+(f \times 0.029)$.

Rate $\leftarrow f+(f \times 0.029)$

ptr $\leftarrow$ random ( ) \% Os

For $(i<O s)$ do

$p t r \leftarrow(i+p t r) \% O s$

If $($ fitness $(p t r)<$ rate $)$ then

$O \leftarrow p t r$

Stop

\section{Simulation Results}

At first Enriched Genetic Algorithm (EGA) has been tested in standard IEEE 118-bus test system [22].The system has 54 generator buses, 64 load buses, 186 branches and 9 of them are with the tap setting transformers. The limits of voltage on generator buses are $0.95-1.1$ per-unit., and on load buses are $0.95-1.05$ per-unit. The limit of transformer rate is $0.9-1.1$, with the changes step 
of 0.025 . The limitations of reactive power source are listed in Table 1, with the change in step of 0.01 .

Table 1: Limitation of reactive power sources

\begin{tabular}{|l|l|l|l|l|l|l|l|}
\hline BUS & 5 & 34 & 37 & 44 & 45 & 46 & 48 \\
\hline QCMAX & 0 & 14 & 0 & 10 & 10 & 10 & 15 \\
\hline QCMIN & -40 & 0 & -25 & 0 & 0 & 0 & 0 \\
\hline BUS & 74 & 79 & 82 & 83 & 105 & 107 & 110 \\
\hline QCMAX & 12 & 20 & 20 & 10 & 20 & 6 & 6 \\
\hline QCMIN & 0 & 0 & 0 & 0 & 0 & 0 & 0 \\
\hline
\end{tabular}

The statistical comparison results of 50 trial runs have been list in Table 2 and the results clearly show the better performance of proposed Enriched Genetic Algorithm (EGA).

Table 2: Comparison results

\begin{tabular}{|l|l|l|l|l|}
\hline Active power loss (p.u) & $\begin{array}{l}\text { BBO } \\
{[\mathbf{2 3}]}\end{array}$ & $\begin{array}{l}\text { ILSBBO/strategy1 } \\
{[\mathbf{2 3}]}\end{array}$ & $\begin{array}{l}\text { ILSBBO/strategy1 } \\
{[\mathbf{2 3}]}\end{array}$ & Proposed EGA \\
\hline Min & 128.77 & 126.98 & 124.78 & 117.94 \\
\hline Max & 132.64 & 137.34 & 132.39 & 118.02 \\
\hline Average & 130.21 & 130.37 & 129.22 & 120.86 \\
\hline
\end{tabular}

Then the Enriched Genetic Algorithm (EGA) has been tested in practical 191 test system and the following results have been obtained. In Practical 191 test bus system - Number of Generators $=$ 20 , Number of lines $=200$, Number of buses $=191$ Number of transmission lines $=55$. Table 3 shows the optimal control values of practical 191 test system obtained by EGA method. And table 4 shows the results about the value of the real power loss by obtained by Enriched Genetic Algorithm (EGA).

Table 3: Optimal Control values of Practical 191 utility (Indian) system by EGA method

\begin{tabular}{|c|c|c|c|c|c|c|c|}
\hline \multirow{2}{*}{\multicolumn{2}{|c|}{$\begin{array}{l}\text { VG1 } \\
\text { VG }\end{array}$}} & \multicolumn{2}{|l|}{1.10} & & \multicolumn{2}{|l|}{ VG 11} & 0.90 \\
\hline & & \multicolumn{2}{|l|}{0.72} & & \multicolumn{2}{|l|}{ VG 12} & 1.00 \\
\hline VG 3 & & \multicolumn{2}{|l|}{1.01} & & \multicolumn{2}{|l|}{ VG 13} & 1.00 \\
\hline VG 4 & & \multicolumn{2}{|l|}{1.01} & & \multicolumn{2}{|l|}{ VG 14} & 0.90 \\
\hline VG 5 & & \multicolumn{2}{|l|}{1.10} & & \multicolumn{2}{|l|}{ VG 15} & 1.00 \\
\hline VG 6 & & \multicolumn{2}{|l|}{1.10} & & \multicolumn{2}{|l|}{ VG 16} & 1.00 \\
\hline VG 7 & & \multicolumn{2}{|l|}{\begin{tabular}{|l}
1.10 \\
\end{tabular}} & & \multicolumn{2}{|l|}{ VG 17} & 0.90 \\
\hline VG 8 & & \multicolumn{2}{|l|}{1.01} & & \multicolumn{2}{|l|}{ VG 18} & 1.00 \\
\hline VG 9 & & \multicolumn{2}{|l|}{1.10} & & \multicolumn{2}{|l|}{ VG 19} & 1.10 \\
\hline VG 10 & & \multicolumn{2}{|l|}{1.01} & & \multicolumn{2}{|l|}{ VG 20} & 1.10 \\
\hline $\mathrm{T} 1$ & 1.00 & & T21 & 0.90 & & $\mathrm{~T} 41$ & 0.90 \\
\hline $\mathrm{T} 2$ & 1.00 & & T22 & 0.90 & & $\mathrm{~T} 42$ & 0.90 \\
\hline T3 & 1.00 & & T23 & 0.90 & & $\mathrm{~T} 43$ & 0.91 \\
\hline $\mathrm{T} 4$ & 1.10 & & T24 & 0.90 & & T44 & 0.91 \\
\hline T5 & 1.00 & & T25 & 0.90 & & $\mathrm{~T} 45$ & 0.91 \\
\hline
\end{tabular}




\begin{tabular}{|c|c|c|c|c|c|}
\hline T6 & 1.00 & T26 & 1.00 & T46 & 0.90 \\
\hline $\mathrm{T} 7$ & 1.00 & T27 & 0.90 & T47 & 0.91 \\
\hline $\mathrm{T} 8$ & 1.01 & T28 & 0.90 & T48 & 1.00 \\
\hline T9 & 1.00 & T29 & 1.01 & T49 & 0.90 \\
\hline T10 & 1.00 & T30 & 0.90 & T50 & 0.90 \\
\hline T11 & 0.90 & T31 & 0.90 & T51 & 0.90 \\
\hline T12 & 1.00 & T32 & 0.90 & T52 & 0.90 \\
\hline T13 & 1.01 & T33 & 1.01 & T53 & 1.00 \\
\hline T14 & 1.01 & T34 & 0.90 & T54 & 0.90 \\
\hline T15 & 1.01 & T35 & 0.90 & T55 & 0.90 \\
\hline T19 & 1.02 & T39 & 0.90 & & \\
\hline T20 & 1.01 & T40 & 0.90 & & \\
\hline
\end{tabular}

Table 4: Optimum real power loss values obtained for practical 191 utility (Indian) systems by EGA method.

\begin{tabular}{l|l}
\hline Real power Loss (MW) & EGA \\
\hline Min & 143.014 \\
\hline Max & 146.082 \\
\hline Average & 144.004 \\
\hline
\end{tabular}

\section{Conclusion}

Enriched Genetic Algorithm (EGA) has been successfully applied for solving reactive power problem. And it has been tested in standard IEEE 118 \& practical 191 bus test systems. Performance comparisons with well-known population-based algorithms give superior results. Enriched Genetic Algorithm (EGA) comes out to find enhanced solutions when compared to that of other reported standard algorithms. The simulation results presented in former section prove the capability of EGA approach to arrive at near to global optimal solution.

\section{References}

[1] O.Alsac, and B. Scott, "Optimal load flow with steady state security",IEEE Transaction. PAS 1973, pp. 745-751.

[2] Lee K Y ,Paru Y M , Oritz J L -A united approach to optimal real and reactive power dispatch , IEEE Transactions on power Apparatus and systems 1985: PAS-104 : 1147-1153

[3] A.Monticelli , M .V.F Pereira ,and S. Granville, "Security constrained optimal power flow with post contingency corrective rescheduling", IEEE Transactions on Power Systems :PWRS-2, No. 1, pp.175-182.,1987.

[4] Deeb N ,Shahidehpur S.M ,Linear reactive power optimization in a large power network using the decomposition approach. IEEE Transactions on power system 1990: 5(2) : 428-435

[5] E. Hobson ,'Network consrained reactive power control using linear programming, ' IEEE Transactions on power systems PAS -99 (4),pp 868=877, 1980

[6] K.Y Lee ,Y.M Park, and J.L Oritz, "Fuel -cost optimization for both real and reactive power dispatches", IEE Proc; 131C,(3), pp.85-93.

[7] M.K. Mangoli, and K.Y. Lee, "Optimal real and reactive power control using linear programming”, Electr.Power Syst.Res, Vol.26, pp.1-10,1993. 
[8] C.A. Canizares , A.C.Z.de Souza and V.H. Quintana, " Comparison of performance indices for detection of proximity to voltage collapse ,' vol. 11. no.3, pp.1441-1450, Aug 1996 .

[9] S.R.Paranjothi , and K.Anburaja, "Optimal power flow using refined genetic algorithm", Electr.Power Compon.Syst, Vol. 30, 1055-1063,2002.

[10] D. Devaraj, and B. Yeganarayana, "Genetic algorithm based optimal power flow for security enhancement", IEE proc-Generation.Transmission and. Distribution; 152, 6 November 2005.

[11] A. Berizzi, C. Bovo, M. Merlo, and M. Delfanti, "A ga approach to compare orpf objective functions including secondary voltage regulation," Electric Power Systems Research, vol. 84, no. 1, pp. $187-194,2012$.

[12] C.-F. Yang, G. G. Lai, C.-H. Lee, C.-T. Su, and G. W. Chang, "Optimal setting of reactive compensation devices with an improved voltage stability index for voltage stability enhancement," International Journal of Electrical Power and Energy Systems, vol. 37, no. 1, pp. $50-57,2012$.

[13] P. Roy, S. Ghoshal, and S. Thakur, "Optimal var control for improvements in voltage profiles and for real power loss minimization using biogeography based optimization," International Journal of Electrical Power and Energy Systems, vol. 43, no. 1, pp. 830 - 838, 2012.

[14] B. Venkatesh, G. Sadasivam, and M. Khan, "A new optimal reactive power scheduling method for loss minimization and voltage stability margin maximization using successive multi-objective fuzzy lp technique," IEEE Transactions on Power Systems, vol. 15, no. 2, pp. 844 - 851, may 2000.

[15] W. Yan, S. Lu, and D. Yu, "A novel optimal reactive power dispatch method based on an improved hybrid evolutionary programming technique," IEEE Transactions on Power Systems, vol. 19, no. 2, pp. 913 - 918, may 2004.

[16] W. Yan, F. Liu, C. Chung, and K. Wong, "A hybrid genetic algorithminterior point method for optimal reactive power flow," IEEE Transactions on Power Systems, vol. 21, no. 3, pp. 1163 1169, aug. 2006.

[17] J. Yu, W. Yan, W. Li, C. Chung, and K. Wong, "An unfixed piecewiseoptimal reactive powerflow model and its algorithm for ac-dc systems," IEEE Transactions on Power Systems, vol. 23, no. 1, pp. $170-176$, feb. 2008.

[18] F. Capitanescu, "Assessing reactive power reserves with respect to operating constraints and voltage stability," IEEE Transactions on Power Systems, vol. 26, no. 4, pp. 2224-2234, nov. 2011.

[19] Z. Hu, X. Wang, and G. Taylor, "Stochastic optimal reactive power dispatch: Formulation and solution method," International Journal of Electrical Power and Energy Systems, vol. 32, no. 6, pp. $615-621,2010$.

[20] A. Kargarian, M. Raoofat, and M. Mohammadi, "Probabilistic reactive power procurement in hybrid electricity markets with uncertain loads," Electric Power Systems Research, vol. 82, no. 1, pp. $68-80,2012$.

[21] Mohammed Bin Jubeir, Mishal Almazrooie, \& Rosni Abdullah, "Enhanced selection method for genetic algorithm to solve traveling salesman problem in Zulikha, J. \& N. H. Zakaria (Eds.)", Proceedings of the 6th International Conference of Computing \& Informatics (pp 69-76), 2017.

[22] IEEE, "The IEEE 30-bus test system and the IEEE 118-test system", (1993), http://www.ee.washington.edu/trsearch/pstca/.

[23] Jiangtao Cao, Fuli Wang and Ping Li, "An Improved Biogeography-based Optimization Algorithm for Optimal Reactive Power Flow", International Journal of Control and Automation Vol.7, No.3 (2014), pp.161-176.

*Corresponding author.

E-mail address: gklenin@ gmail.com 